\title{
Probabilistic evaluation of target dose deterioration in dose painting by numbers for stage II/III lung cancer
}

Citation for published version (APA):

Fontanarosa, D., Witte, M., Meijer, G., Shakirin, G., Steenhuijsen, J., Schuring, D., van Herk, M., \& Lambin, P. (2015). Probabilistic evaluation of target dose deterioration in dose painting by numbers for stage II/III lung cancer. Practical radiation oncology, 5(4), e375-e382.

https://doi.org/10.1016/j.prro.2015.01.001

Document status and date:

Published: 01/01/2015

DOI:

10.1016/j.prro.2015.01.001

Document Version:

Publisher's PDF, also known as Version of record

Document license:

Taverne

\section{Please check the document version of this publication:}

- A submitted manuscript is the version of the article upon submission and before peer-review. There can be important differences between the submitted version and the official published version of record.

People interested in the research are advised to contact the author for the final version of the publication, or visit the DOI to the publisher's website.

- The final author version and the galley proof are versions of the publication after peer review.

- The final published version features the final layout of the paper including the volume, issue and page numbers.

Link to publication

\footnotetext{
General rights rights.

- You may freely distribute the URL identifying the publication in the public portal. please follow below link for the End User Agreement:

www.umlib.nl/taverne-license

Take down policy

If you believe that this document breaches copyright please contact us at:

repository@maastrichtuniversity.nl

providing details and we will investigate your claim.
}

Copyright and moral rights for the publications made accessible in the public portal are retained by the authors and/or other copyright owners and it is a condition of accessing publications that users recognise and abide by the legal requirements associated with these

- Users may download and print one copy of any publication from the public portal for the purpose of private study or research.

- You may not further distribute the material or use it for any profit-making activity or commercial gain

If the publication is distributed under the terms of Article $25 \mathrm{fa}$ of the Dutch Copyright Act, indicated by the "Taverne" license above, 

stage II/III lung cancer

\author{
Davide Fontanarosa PhD a,b,*, Marnix Witte PhD ${ }^{c}$, Gert Meijer PhD d, \\ Georgy Shakirin PhD ${ }^{e}$, Jacco Steenhuijsen PhD ${ }^{f}$, Danny Schuring PhD ${ }^{f}$, \\ Marcel van Herk PhD ${ }^{c, 1}$, Philippe Lambin PhD ${ }^{\text {b, } 1}$
}

\author{
a Philips Research, Oncology Solutions, Eindhoven, The Netherlands \\ ${ }^{\mathrm{b}}$ Department of Radiation Oncology (MAASTRO), GROW - School for Oncology and Developmental Biology, Maastricht \\ University Medical Center, Maastricht, The Netherlands \\ ${ }^{\mathrm{c}}$ Department of Radiation Oncology, Netherlands Cancer Institute and Antoni van Leeuwenhoek Hospital, Amsterdam, The Netherlands \\ ${ }^{\mathrm{d}}$ Department of Radiotherapy, University Medical Center, Utrecht, The Netherlands \\ e Philips Technologie GmbH Innovative Technologies, Research Laboratories, Aachen, Germany \\ ${ }_{\mathrm{f}}^{\mathrm{f}}$ epartment of Radiotherapy, Catharina Hospital, Eindhoven, the Netherlands
}

Received 4 July 2014; revised 27 November 2014; accepted 6 January 2015

\begin{abstract}
Purpose: Non-small cell lung cancer is typically irradiated with 60-66 Gy in 2-Gy fractions. Local control could be improved by increasing dose to the more radiation-resistant areas (eg, based on the standardized uptake values of a pretreatment $\left[{ }^{18} \mathrm{~F}\right]$ fluoro-deoxyglucose positron emission tomography scan). Such dose painting approaches, however, are poorly suited for a conventional planning target volume margin expansion; therefore, typically no margins are used. This study investigates dose deterioration of a dose painting by numbers (DPBN) approach resulting from geometrical uncertainties.

Methods and materials: For 9 DPBN plans of stage II/III non-small cell lung cancer patients, the boost dose was escalated up to $130 \mathrm{~Gy}$ (in 33 fractions) or until a dose-limiting constraint was reached. Then, using Monte Carlo methods, a probabilistic evaluation of dose endpoints for $99 \%, 98 \%$, and $2 \%$ of gross tumor volume at a $90 \%$ confidence level was performed considering 8 different combinations of systematic $\left(\sum\right)$ and random $(\sigma)$ geometric error distributions.

Results: Important underdosages, because of geometric uncertainties, of up to $38 \mathrm{~Gy}$ with minimal image guidance occur, reducing to 8 Gy with the highest level of image guidance, for a patient where a maximum dose of 119 Gy could be achieved. The evaluation showed that systematic errors had the largest influence. The effects of the uncertainties are most evident where the dose or its gradient is high.
\end{abstract}

Supplementary material for this article (http://dx.doi.org/10.1016/j.prro.2015.01.001) can be found at www.practicalradonc.org.

Sources of support: This research was supported by the Center for Translational Molecular Medicine AIRFORCE project. This research was also supported by the Dutch Technology Foundation STW (grant number 10696 DuCAT), which is the applied science division of NWO, and the Technology Programme of the Ministry of Economic Affairs.

Conflicts of interest: None.

* Corresponding author. Philips Research, Oncology Solutions, High Tech Campus 34, 5656AE, Eindhoven, The Netherlands.

E-mail address: davide.fontanarosa@philips.com (D. Fontanarosa).

${ }^{1}$ M.v.H. and P.L. contributed equally to this work. 
Conclusions: Probabilistic evaluation showed that the geometric uncertainties have a large effect and should be evaluated before approving DPBN plans.

(C) 2015 American Society for Radiation Oncology. Published by Elsevier Inc. All rights reserved.

\section{Introduction}

Several preclinical and clinical studies have shown that tumor control probability depends on biological properties of the tumor-such as hypoxia, proliferation, and metabolism. ${ }^{1-5}$ Therefore, it seems reasonable to include the tumor biological information of an individual patient in the treatment planning process. ${ }^{6}$ For example, it has been shown that tumor relapse often occurs mostly in areas of high metabolism imaged with $\left[{ }^{18} \mathrm{~F}\right]$ fluoro-deoxyglucose (FDG) positron emission tomography (PET). ${ }^{1,6-10}$ Treatment strategies aimed at prescribing dose based on the biological information provided by functional imaging are known as dose painting ${ }^{11}$ and simulations and clinical investigations have been published. ${ }^{3,12-15}$ However, there is no consensus on how to escalate dose based on additional information provided by PET imaging. ${ }^{16}$ Several groups have proposed using a threshold and escalating the dose to a target subvolume of high tracer uptake named biological target volume. This method can be referred to as dose painting by contours (DPBC). ${ }^{17}$ Another approach known as dose painting by numbers (DPBN) is to prescribe dose on a voxel-by-voxel basis as a function of the local standardized uptake value (SUV). ${ }^{18}$

The standard clinical procedure to handle geometric uncertainties is to derive margins based on the standard deviations of the systematic and random geometrical errors of the clinical target volume (CTV). ${ }^{19}$ Several recipes exist for expanding the CTV to the planning treatment volume (PTV) using measured or assumed uncertainty values. ${ }^{20-23}$

For nonuniform dose prescriptions, as in DPBN, margins are not a proper tool to ensure target coverage; the prescription in principle has a different value on each voxel of the CTV or of the gross tumor volume (GTV), and the concept of margin cannot be applied. ${ }^{24}$ Simply proceeding without margins ignores the unavoidable presence of geometric uncertainties. A possible solution is to apply probabilistic planning for treatment plan optimization ${ }^{25-29}$ and probabilistic evaluation for evaluation of target coverage. ${ }^{30}$ With this approach, uncertainties are incorporated directly during planning or evaluation, simulating the effect of dose to the target.

The aim of this work is to investigate the robustness of typical DPBN plans for geometrical uncertainties using probabilistic evaluation.

\section{Methods and materials}

\section{Study cases}

Nine stage II and III non-small cell lung cancer (NSCLC) patients with local lymph node involvement, who were part of a group previously investigated in another work, ${ }^{24}$ were included. In that work, DPBN and DPBC plans were compared. The DPBN plans were used for this work: for all patients, conventional 3-dimensional PET and coregistered 4-dimensional computed tomography $(1 \mathrm{~mm} \times 1 \mathrm{~mm} \times 3 \mathrm{~mm}$ pixel size $)$ scans were available (Philips Gemini PET-CT scanner, Philips Medical Systems BV, Best, The Netherlands). The SUV in the GTV was at least 4. The GTV delineation was performed on the mid-ventilation computed tomography scan with a slice thickness of $2 \mathrm{~mm}$. Treatment planning was performed on a research version of the Philips Pinnacle $^{3}$ treatment planning system (version 9.100, Philips Radiation Oncology Systems, Fitchburg, WI). The dose calculation engine implemented in the treatment planning system is a collapsed cone convolution superposition algorithm, in particular its "adaptive convolve" version, which was proven reliable in this body region and for this type of applications. ${ }^{31}$

\section{Organs at risk}

The organs at risk delineated and considered for this study included lungs, spinal cord, brachial plexus, esophagus, trachea, bronchial tree, heart, and the separate large vessels within the mediastinum. For the spinal cord, brachial plexus and the combined mediastinal structures (heart, vessels, trachea, and main bronchi), planning at risk volumes (PRV) also were created using a 5-mm expansion. The dose-limiting structures used in the following section and the maximum accepted values were as follows.

1. Mean lung dose: less than $20 \mathrm{~Gy}$.

2. Lung volume receiving 20 Gy or more: less than $35 \%$.

3. Oesophagus volume receiving 35 Gy or more: less than $65 \%$.

4. Mean heart dose: less than $46 \mathrm{~Gy}$.

5. Maximum dose to PRV spinal cord: less than $50 \mathrm{~Gy}$.

6. Maximum dose to PRV brachial plexus: less than $66 \mathrm{~Gy}$.

7. Maximum dose to PRV large vessels, heart, trachea, and main bronchi: less than $76 \mathrm{~Gy}$.

\section{DPBN}

With DPBN, the entire GTV of the primary tumor is considered the boost region. Our DPBN strategy aims for a linear relationship between the prescription dose to a voxel and the underlying SUV (Eq. (1)). ${ }^{18}$ DPBN plans were prepared (with no separation between baseline plan and boost) to be delivered in 33 fractions for each patient. They were generated using direct machine parameter 
Table 1 Max dose, mean dose, target volumes and locations, maximum SUV values, and structures that limited dose escalation in the DPBN plans

\begin{tabular}{lrrrlrl}
\hline $\begin{array}{l}\text { Patient } \\
\text { number }\end{array}$ & $\begin{array}{l}\text { Max } \\
\text { dose } \\
(\mathrm{Gy})\end{array}$ & $\begin{array}{l}\text { Mean } \\
\text { dose }\end{array}$ & $\begin{array}{l}\text { GTV } \\
\left(\mathrm{cm}^{3}\right)\end{array}$ & $\begin{array}{l}\text { Location } \\
\text { primary } \\
\text { tumor }\end{array}$ & & $\begin{array}{l}\mathrm{SUV}_{\max } \\
\text { limiting } \\
\text { structure }\end{array}$ \\
\hline 1 & 86 & 77 & 119 & LUL & 6.7 & Aorta \\
2 & 84 & 76 & 33 & LUL & 10.2 & LAP \\
3 & 130 & 97 & 27 & RLL & 5.6 & - \\
4 & 130 & 104 & 30 & LUL & 9.3 & - \\
5 & 120 & 97 & 572 & RUL & 17.3 & Lungs \\
6 & 130 & 89 & 61 & RLL & 8.3 & BT + \\
& & & & & & aorta \\
7 & 130 & 113 & 180 & RLL & 6.6 & - \\
8 & 86 & 77 & 25 & RML & 6.5 & RPA \\
9 & 119 & 92 & 96 & LUL & 14.7 & LAP \\
\hline
\end{tabular}

$\mathrm{BT}$, bronchial tree; DPBN, dose painting by numbers; Gy, Gray; LAP, left pulmonary artery; LUL, left upper lobe; max, maximum; RLL, right lower lobe; RML, right middle lobe; RPA, right pulmonary artery; RUL, right upper lobe; SUV, standardized uptake value.

optimization, ${ }^{32}$ with a dose grid covering the entire chest with a resolution of $2 \mathrm{~mm}$. A research plugin was used with a single threshold model for calculation of the prescribed dose based on SUV on voxel-by-voxel basis:

$$
\begin{aligned}
& D_{i}=\left\{\begin{array}{l}
D_{\min }, \\
D_{\text {min }}
\end{array}+\frac{D_{\max }-D_{\min }}{S U V_{\text {high }}-S U V_{\text {low }}}\left(S U V_{i}-S U V_{\text {low }}\right),\right. \\
& S U V_{i} \leq S U V_{\text {low }} \\
& S U V_{\text {low }}<S U V_{i} \leq S U V_{\text {high }}
\end{aligned}
$$

where $\mathrm{D}_{\min }, \mathrm{D}_{\max }$, and $\mathrm{D}_{\mathrm{i}}$ are the minimum and maximum prescribed doses and prescribed dose in voxel i, respectively, and $\mathrm{SUV}_{\text {low }}, \mathrm{SUV}_{\text {high }}$, and $\mathrm{SUV}_{\mathrm{i}}$ are the lower and upper SUV thresholds and SUV in voxel $\mathrm{i}$, respectively. For $\mathrm{SUV}_{\text {low }}$ and $\mathrm{SUV}_{\text {high }}$ in this work, the minimum and maximum SUV within the GTV were taken. The baseline dose $\left(\mathrm{D}_{\min }\right)$ was 66 Gy in 2-Gy fractions. The boost dose $\left(D_{\max }\right)$ was increased up to a maximum value of $130 \mathrm{~Gy}$ or until 1 of the dose-limiting constraints reported in the Organs at risk section was reached. The optimization process was aimed at minimizing a cost function proportional to sum of the normalized quadratic differences on a voxel basis between the locally prescribed dose and the calculated dose within the target. Eleven 6-MV equidistant beams were used for each patient, with no beams entering through the contralateral lung. The direct machine parameter optimization plans used a multileaf collimator with 4-mm leaf width, with maximum number of segments set to 60 , minimum segment area to $2 \mathrm{~cm}^{2}$, and minimum number of monitor units per segment to 2 .

The optimizations were performed using combinations of minimum dose and maximum dose research objectives on the GTVs (both the primary tumor and the lymph nodes) incorporating DPBN. Dose escalation was halted when more than $15 \%$ of the voxels inside the GTV had a dose lower than $95 \%$ of the prescribed voxel dose (ie, when dose-limiting organs excessively restricted the dose to the target). A summary of patient, dose, and target statistics is shown in Table 1.

\section{Accounting for geometric uncertainties}

Systematic errors $\left(\sum\right)$ correspond to the difference between the planning geometry and the average geometry over all treatment fractions. In our study, the systematic errors included a systematic component of setup uncertainty and a baseline shift. The random errors $(\sigma)$ are the differences between the average treatment geometry and the day-to-day geometries: they refer to errors arising from the positioning of the patient for each fraction, daily baseline shifts, and breathing.

In this work, we simulated different $\sum$ and $\sigma$ values; in particular the following combinations were used (in millimeters): $\left(\sum, \sigma\right)=(0,0) ;(5,2) ;(4,2) ;(3,4) ;(3,3) ;(3,2) ;(2,3) ;(2,2) ;(1,2)$.

These values represent a range from no image guidance at all to daily image guidance. ${ }^{33}$

To be able to draw general conclusions and limit the possible combinations, we decided to simulate only error distributions that are isotropic in left-right, anteroposterior, and superoinferior directions. This standard conservative approach, based on equivalence with the original van Herk recipe (where the margin expansion is $2.5 \sum+0.7 \sigma$, with $\sum$ systematic errors and $\sigma$ random errors ${ }^{21}$ ), does not link our work to any specific interpretation of the still-unsolved problem of respiratory induced asymmetries. ${ }^{34}$

\section{Dose reporting: Probabilistic evaluation}

To summarize the quality of the plan in terms of deviation from the planned dose, we used the concept of $\Delta \mathrm{VH}$, defined as the volume histogram of the difference between the 3-dimensional planned and prescribed dose distributions. ${ }^{30}$ In a $\Delta \mathrm{VH}$, the voxels of a region are binned based not on the value of the dose delivered in that voxel, as in a dose-volume histogram, but on the difference between the dose delivered and the dose prescribed.

Endpoints were calculated using Monte Carlo sampling methods implemented in a standalone software tool, "planJury," developed in-house. For each pair $\left(\sum, \sigma\right)$ reported in the Accounting for geometric uncertainties section, the software performs the following steps:

1. 10,000 values are randomly picked from the Gaussian distribution of displacements with standard deviation $\sum$.

2. A number of values corresponding to the number of treatment fractions (in this case, 33 ) is similarly picked from the Gaussian distribution of displacements with standard deviation $\sigma$ to simulate random errors. 
Table $2 \Delta$ VH values at $99 \%$ of GTV volume $(\Delta 99)$ for 7 combinations of systematic and random errors $\left(\sum, \sigma\right)$

\begin{tabular}{|c|c|c|c|c|c|c|c|c|c|c|c|c|c|c|}
\hline & $\sum_{(\mathrm{mm})}$ & $\begin{array}{l}\sigma \\
(\mathrm{mm})\end{array}$ & $\begin{array}{l}\Delta 99 \\
\text { (Gy) }\end{array}$ & $\begin{array}{l}\Delta 99 \\
\left(\sum, \sigma\right)- \\
\end{array}$ & & $\sum_{(\mathrm{mm})}$ & $\begin{array}{l}\sigma \\
(\mathrm{mm})\end{array}$ & $\begin{array}{l}\Delta 99 \\
(\mathrm{~Gy})\end{array}$ & $\begin{array}{l}\Delta 99 \\
\left(\sum, \sigma\right)-\end{array}$ & & $\sum_{(\mathrm{mm})}$ & $\begin{array}{l}\sigma \\
(\mathrm{mm})\end{array}$ & $\begin{array}{l}\Delta 99 \\
(\mathrm{~Gy})\end{array}$ & $\begin{array}{l}\Delta 99 \\
\left(\sum, \sigma\right)-\end{array}$ \\
\hline & & & & $\begin{array}{l}\Delta 99 \\
(0,0) \\
(\mathrm{Gy})\end{array}$ & & & & & $\begin{array}{l}\Delta 99 \\
(0,0) \\
(\mathrm{Gy})\end{array}$ & & & & & $\begin{array}{l}\Delta 99 \\
(0,0) \\
(\mathrm{Gy})\end{array}$ \\
\hline \multirow[t]{9}{*}{ Patient 1} & 0 & 0 & -10.49 & & Patient 4 & 0 & 0 & -6.33 & & Patient 7 & 0 & 0 & -12.80 & \\
\hline & 5 & 2 & -12.19 & -1.70 & & 5 & 2 & -41.82 & -35.49 & & 5 & 2 & -35.85 & -23.05 \\
\hline & 4 & 2 & -11.80 & -1.31 & & 4 & 2 & -35.77 & -29.44 & & 4 & 2 & -31.75 & -18.95 \\
\hline & 3 & 4 & -11.42 & -0.93 & & 3 & 4 & -28.92 & -22.59 & & 3 & 4 & -26.60 & -13.80 \\
\hline & 3 & 3 & -11.04 & -0.55 & & 3 & 3 & -21.39 & -15.06 & & 3 & 3 & -21.23 & -8.43 \\
\hline & 3 & 2 & -11.40 & -0.91 & & 3 & 2 & -30.59 & -24.26 & & 3 & 2 & -27.39 & -14.59 \\
\hline & 2 & 3 & -11.40 & -0.91 & & 2 & 3 & -29.53 & -23.20 & & 2 & 3 & -26.85 & -14.05 \\
\hline & 2 & 2 & -11.02 & -0.53 & & 2 & 2 & -28.93 & -22.60 & & 2 & 2 & -21.95 & -9.15 \\
\hline & 1 & 2 & -10.71 & -0.22 & & 1 & 2 & -13.87 & -7.54 & & 1 & 2 & -16.37 & -3.57 \\
\hline \multirow[t]{9}{*}{ Patient 2} & 0 & 0 & -6.73 & & Patient 5 & 0 & 0 & -17.74 & & Patient 8 & 0 & 0 & -8.91 & \\
\hline & 5 & 2 & -10.40 & -3.67 & & 5 & 2 & -31.10 & -13.36 & & 5 & 2 & -13.31 & -4.40 \\
\hline & 4 & 2 & -9.24 & -2.51 & & 4 & 2 & -27.34 & -9.60 & & 4 & 2 & -12.40 & -3.49 \\
\hline & 3 & 4 & -8.40 & -1.67 & & 3 & 4 & -23.80 & -6.06 & & 3 & 4 & -11.21 & -2.30 \\
\hline & 3 & 3 & -7.72 & -0.99 & & 3 & 3 & -20.87 & -3.13 & & 3 & 3 & -10.03 & -1.12 \\
\hline & 3 & 2 & -8.51 & -1.78 & & 3 & 2 & -24.04 & -6.30 & & 3 & 2 & -10.82 & -1.91 \\
\hline & 2 & 3 & -8.40 & -1.67 & & 2 & 3 & -23.85 & -6.11 & & 2 & 3 & -10.98 & -2.07 \\
\hline & 2 & 2 & -7.72 & -0.99 & & 2 & 2 & -21.04 & -3.30 & & 2 & 2 & -10.34 & -1.43 \\
\hline & 1 & 2 & -7.17 & -0.44 & & 1 & 2 & -18.99 & -1.25 & & 1 & 2 & -9.73 & -0.82 \\
\hline \multirow[t]{9}{*}{ Patient 3} & 0 & 0 & -5.36 & & Patient 6 & 0 & 0 & -30.80 & & Patient 9 & 0 & 0 & -17.54 & \\
\hline & 5 & 2 & -43.19 & -37.83 & & 5 & 2 & -60.90 & -30.10 & & 5 & 2 & -33.88 & -16.34 \\
\hline & 4 & 2 & -36.75 & -31.39 & & 4 & 2 & -55.74 & -24.94 & & 4 & 2 & -30.30 & -12.76 \\
\hline & 3 & 4 & -29.34 & -23.98 & & 3 & 4 & -49.50 & -18.70 & & 3 & 4 & -25.72 & -8.18 \\
\hline & 3 & 3 & -21.02 & -15.66 & & 3 & 3 & -42.78 & -11.98 & & 3 & 3 & -20.94 & -3.40 \\
\hline & 3 & 2 & -31.98 & -26.62 & & 3 & 2 & -49.64 & -18.84 & & 3 & 2 & -26.48 & -8.94 \\
\hline & 2 & 3 & -30.34 & -24.98 & & 2 & 3 & -49.37 & -18.57 & & 2 & 3 & -26.00 & -8.46 \\
\hline & 2 & 2 & -23.11 & -17.75 & & 2 & 2 & -42.64 & -11.84 & & 2 & 2 & -22.51 & -4.97 \\
\hline & 1 & 2 & -13.24 & -7.88 & & 1 & 2 & -36.26 & -5.46 & & 1 & 2 & -18.93 & -1.39 \\
\hline
\end{tabular}

The first line for each patient, corresponding to the pair $\left(\sum, \sigma\right)=(0,0)$, is the discrepancy when no errors are considered; the values here reported correspond therefore to what published in Meijer et al. ${ }^{24}$ Differences in $\Delta \mathrm{VH}$ values with respect to the reported $\left(\sum, \sigma\right)$ and $(0,0)$ systematic and random errors at $99 \%$ of GTV volumes are also reported. Differences up to 38 Gy can be seen (patient $3,\left(\sum, \sigma\right)=(5,2)$ ).

$\mathrm{GTV}$, gross tumor volume; Gy, Gray; $\Delta \mathrm{VH}$, volume histogram of the difference between the 3-dimensional planned and prescribed dose distributions.

3. All the random errors (point 2) are added to each of the systematic errors (point 1).

4. Each of the 10,000 errors, including the systematic and the random components created at point 3 , is applied to the target, which is then displaced 10,000 times with respect to the dose grid.

5. For each position in point 4 and for each voxel of the target, the dose value obtained after the shift is subtracted from the dose value without the shift (the original prescribed dose).

6 . The resulting dose values are plotted as target $\Delta \mathrm{VHs}, 1$ for each displacement.

7. The $10,000 \Delta \mathrm{VH}$ are then sorted according to the value at $99 \%$ of the target volume.

8. The best $90 \%$ of the $\Delta \mathrm{VHs}$ (those that were able to least underdose the target) is selected.

9. Of these, the worst $\Delta \mathrm{VH}$ is selected and reported. This corresponds to a confidence level of $90 \%$.
If this value does not exceed $5 \%$ of the maximum prescription value at $99 \%$ of the volume, a nonuniform dose distribution is obtained that has similar geometrical robustness as a conventional margin-based plan with a uniform dose prescription. ${ }^{30}$

In our work, we used the $\Delta \mathrm{VH}$ values at $99 \%$ as the main endpoint (referred to, from this point on, as $\Delta 99$ ) of the target volume. In practice, this is the loss of dose to $99 \%$ of the GTV (at $90 \%$ confidence), when uncertainties are considered in the plan, with respect to the planned dose without uncertainties.

For completeness, the values at $98 \%(\Delta 98)$ and $2 \%$ $(\Delta 2)$ of the volume (calculated using a similar approach as that deribed in the previous paragraph) and the mean value $(\Delta$ mean $)$ were also reported. Normalization to 33 fractions $\times 2$ Gy for an alpha/beta ratio of 10 Gy was performed. 

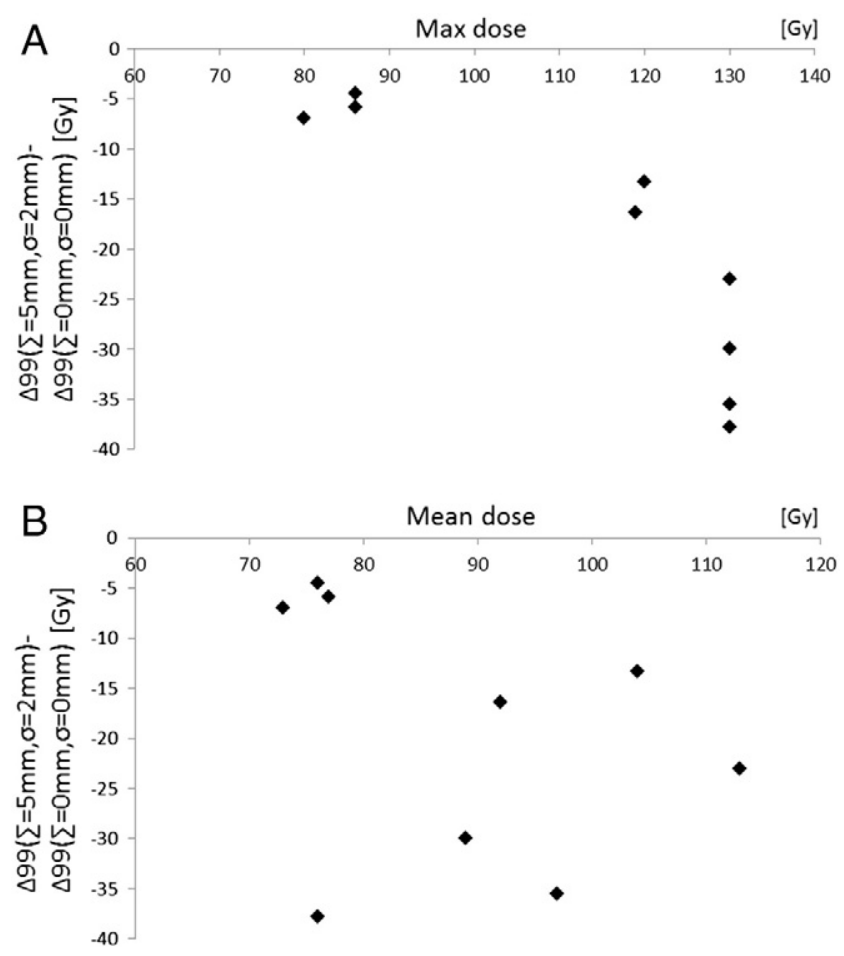

Figure 1 Difference in $\Delta \mathrm{VH}$ values (the volume histogram of the difference between the 3-dimensional planned and prescribed dose distributions) at $99 \%$ of gross target volume with $\left(\sum, \sigma\right)=(5,2)$ and $\left(\sum, \sigma\right)=(0,0)$ as a function of $(\mathrm{A})$ maximum dose and $(\mathrm{B})$ mean dose achieved with the plan.
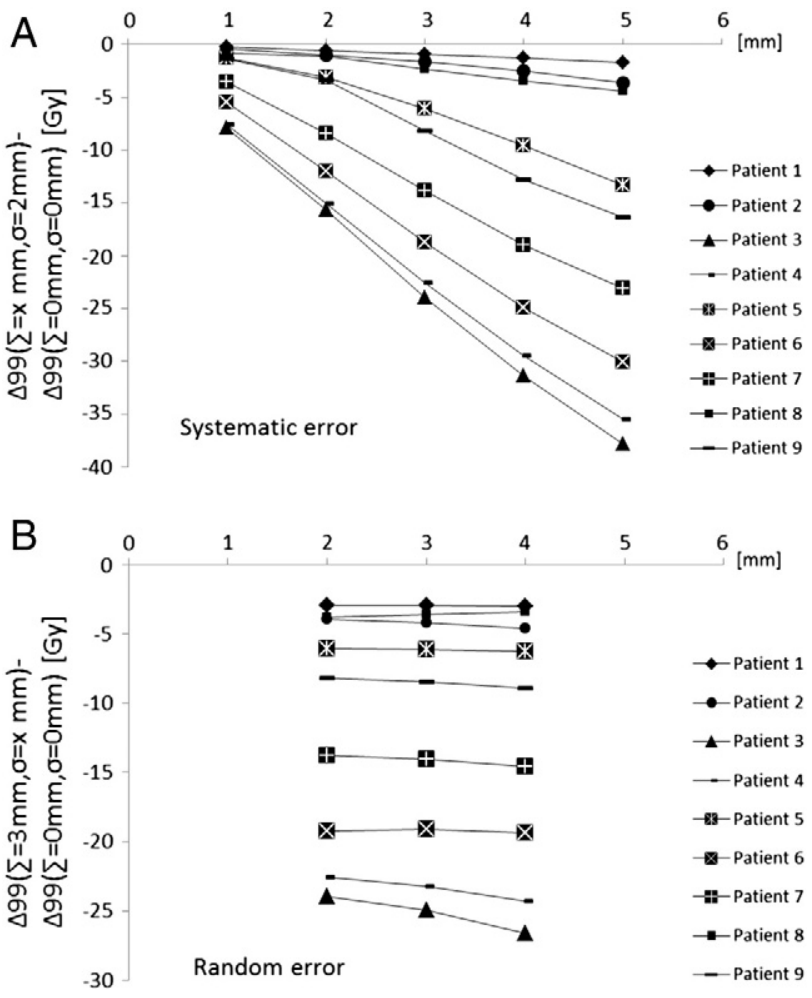

Figure 2 Difference between $\Delta \mathrm{VH}$ (the volume histogram of the difference between the 3-dimensional planned and prescribed dose distributions) values at $99 \%$ of gross target volume with varying (A) systematic and (B) random errors with respect to $\left(\sum, \sigma\right)=(0,0)$. 
Finally, to enable visual inspection and aid geometric interpretation of the results, a plugin was implemented in the Pinnacle ${ }^{3}$ treatment planning system, research version, using fixed (not randomly generated) shifts in space: for all the patients, a $\Delta \mathrm{VH}$ was recalculated shifting the dose volume $\pm 4 \mathrm{~mm}$ along the craniocaudal, laterolateral, and anteroposterior directions; the position of the point of maximum dose discrepancy after the shifts was also evaluated. In this work, an assumption (dose cloud assumption) was made of equivalence between $\Delta \mathrm{VH}$ recalculation when dose volume is shifted and when dose is recomputed after isocenter (IC) shift, based on results presented in the literature. ${ }^{35}$ To test the assumption in very heterogeneous situations, both in dose and in density distributions, as those presented here, the same study was performed applying the same shifts to the IC of the treatment and recomputing dose after each shift.

\section{Results}

In Table 2, $\Delta 99$ for the GTV is reported for the 9 patients for the different combinations of geometric errors reported in the Accounting for geometric uncertainties section. The $\Delta 98$ and $\Delta 2$ are reported in the supplementary material. Table 2 also shows that, when errors are taken into account, a larger difference between prescribed and actually delivered dose is observed. The differences between the endpoint values calculated with the different combinations of $\left(\sum, \sigma\right)$ and calculated with $\left(\sum=0, \sigma=0\right)$ are also shown; these values indicate the impact of geometric uncertainties on the ability to paint dose on a nonuniform dose prescription distribution. Differences can be as high as $38 \mathrm{~Gy}$ (patient $3, \sum=5 \mathrm{~mm}$, $\sigma=2 \mathrm{~mm}$ ). They seem to increase, within the limited statistical data available, with maximum dose (Fig 1A) but show little correlation with mean dose (Fig 1B). A strong correlation is evident between systematic errors and dose difference with respect to the $\left(\sum=0, \sigma=0\right)$ case on $\Delta 99$ (Fig 2A), whereas the correlation with random errors is weak (Fig 2B).

The average values of the $\Delta 99$ endpoint values after the shifts, both applied to the dose distributions and to the treatment IC (see Dose reporting: Probabilistic evaluation), for the 9 patients (Supplementary Table 2) are very similar to the values reported for the probabilistic evaluations of Table 2 (4-mm systematic error column). After each of these shifts, the point corresponding to the maximum dose difference between prescription and calculated dose distribution is always along the highest dose gradient along the direction of the shift (Supplementary Fig 1).

The evaluation calculation time, with the hardware available (Philips 810x workstation), was always shorter than a minute.

\section{Discussion}

If a free-breathing PET scan is used for contouring the target, this could partially account for the breathing part of random errors. But this work shows that the main contribution to discrepancies between what is planned and what is actually delivered is from systematic errors. A free-breathing PET scan is not sufficient for accurate planning because it compensates for random uncertainties by smearing the PET signal corresponding to different positions of the target in the breathing cycle. This, however, does not compensate for systematic mismatches that might happen during patient positioning for imaging and irradiation. ${ }^{36-38}$

The discrepancies are in great part from high-dose regions, corresponding to peak values of the PET scan. In fact, the shifts create the largest discrepancies where the dose gradients are steeper, and this typically happens for high-dose values, with these highly nonuniform dose prescriptions. Near low-dose areas, instead, because a baseline value of 66 Gy was set on the CTV, the shifts produced less variation in the $\Delta \mathrm{VH}$. The geometrical complexity of the target and of the prescription dose volume among the different patients may allow for different points of maximum dose difference between delivered and prescribed distributions for the different fixed shifts-meaning that shifting the dose distribution in 1 direction might produce a maximum difference point different than moving it in another direction, but they always appear in maximum dose and maximum dosegradient areas.

If a $5 \%$ of the maximum prescribed dose threshold is set, meaning that $\Delta 99$ must be smaller than $5 \%$ of the maximum prescribed dose, all the patients would fail to meet this criterion. It is necessary to raise it to $7 \%$ to include the first patient, but with the combination of the smallest systematic and random errors. To include all the patients and the combinations, the threshold should be placed at $46 \%$.

An interesting question arising from this study is whether DPBN is practically feasible. Other authors in the literature question this point (eg, Bowen et $\mathrm{al}^{39}$ ), because of insufficient advances in absolute quantification of functional images and improvements in delivery techniques over smaller spatial scales or because of a lack of knowledge about the relationship between functional imaging values and the required dose for local control.

Because the largest differences arise at high-dose and high dose-gradient areas, DPBN is intrinsically sensitive to geometric uncertainties. Other approaches would probably be less subject to these variations. In particular, in our experience, planning that incorporates geometric uncertainties (probabilistic planning ${ }^{30}$ ) might make DPBN similar to DPBC because the effect of shifting the dose is to smooth the dose peaks. It still needs to be addressed 
how the number of levels in the DPBC plans depends on the specific patient, on the complexity of the plan, or on other features to balance accuracy with feasibility. This investigation is part of our future work.

If systematic errors can be reduced to $2 \mathrm{~mm}$ (for example, using online image guidance), better results can be produced in terms of difference in discrepancies, but for some patients still remain quite high (eg, more than 20 Gy for patient 4). The pair $\left(\sum=1 \mathrm{~mm}, \sigma=2 \mathrm{~mm}\right)$ was also considered because it could be achieved with stereotactic techniques: as expected, these values produce the best results, keeping the difference below $8 \mathrm{~Gy}$ for all patients. This indicates that online image guidance is a prerequisite for DPBN. Noteworthy, in Fig 2, 2 different trends can be recognized. For patients 1, 2, and 8, the plans are more robust to increasing systematic errors. For these patients, dose escalation was halted by critical structures, and the maximum dose value reached was around $85 \mathrm{~Gy}$. For the others, instead, doses of 120-130 Gy could be achieved. Among the latter, patients 5, 7, and 9 had the largest GTVs (Table 1) and showed intermediate discrepancies. Patients 3, 4, and 6 had GTV volumes much smaller than patients 5, 7, and 9 and produced the largest discrepancies (Table 2). This produces much steeper dose distributions and shows that, in these cases, target coverage is more degraded with increasing systematic errors, as expected. This also confirms that image guidance is paramount because reducing maximum prescribed dose to contain sensitivity to systematic errors would discard all the benefits of a dose escalation approach.

Although the inclusion of a specific linear particle accelerator in these plans might produce a loss in generality, it was necessary to compare the results with Meijer et al, ${ }^{24}$ in which the same linear particle accelerator and the same settings were used; on the other hand, dealing with a deliverable plan, which typically shows less steep gradients, makes the results achieved more meaningful. In fact, the values obtained for the dose differences would be probably even larger with a plan optimized and not converted. Our conclusions are thus based on reasonable clinical grounds.

Given the extreme values of dose and physical density changes in the cases presented here, the dose cloud assumption was tested performing recalculation of $\Delta 99$ values not only after fixed shifts of the dose distribution, but also shifting the treatment IC and recomputing the dose (see Dose reporting: Probabilistic evaluation). The results show an excellent agreement between $\Delta 99$ values when the dose cloud assumption is made and when proper dose recomputation is performed (Supplementary Table 2 ). This indicates that this approach is robust for lung patients because isolated targets in a less dense environment (such as NSCLC) will keep an unchanged dose distribution when moving within the boundaries of the irradiation field. The correctness of this approach with convolution algorithms (when considering areas not in proximity to the skin) was also presented in Craig et al. ${ }^{35}$
Significant changes can occur in both anatomic and, even more important, biologic image-based GTVs ${ }^{40}$ during the treatment course and may result in a wrong dose deposition. For DPBN treatments, a shrinking GTV, for example, can cause the delivery of a maximum dose to the wrong spot inside the target, whereas for standard uniform dose techniques the correct coverage is always guaranteed (if the target remains inside the PTV). In fact, for standard plans, the PTV expansion takes into account (up to a certain level) changes in organs configuration, whereas in DPBN plans this is not the case because margin expansion is not possible. So a correct DPBN treatment workflow should include treatment adaptation-eg, using an approach as in Duprez et al, ${ }^{41}$ to compensate as much as possible for this effect. And probabilistic evaluation should be run after the initial plan but also after each adaptation to ensure that what is prescribed is also delivered at each stage.

In conclusion, when dose painting planning strategies are used, geometric uncertainties must be properly taken in consideration; otherwise, there is a serious risk of misestimating dose delivery to the target. In particular, systematic are more important than random uncertainties. The software for plan evaluation with uncertainties used in this work was validated and proven reliable. The largest differences between prescribed and delivered dose distributions occur in the high-dose regions, along the highest dose gradients. DPBN optimized without accommodations for geometric uncertainties suffers from an intrinsic difficulty in controlling the high-peak areas when geometric uncertainties are considered. An approach such as DPBC, in which locally uniform dose areas are created, might be less sensitive to these kinds of problem.

\section{Acknowledgment}

The authors wish to thank Dr Matthieu Bal from Philips Healthcare, Eindhoven, The Netherlands, for providing the research version of Pinnacle. Dr Wouter van Elmpt is thanked for the valuable contribution to the discussion.

\section{References}

1. Abramyuk A, Tokalov S, Zophel K, et al. Is pre-therapeutical FDG-PET/CT capable to detect high risk tumor subvolumes responsible for local failure in non-small cell lung cancer? Radiother Oncol. 2009;91:399-404.

2. Levine EA, Farmer MR, Clark P, et al. Predictive value of 18-fluoro-deoxy-glucose-positron emission tomography (18FFDG-PET) in the identification of responders to chemoradiation therapy for the treatment of locally advanced esophageal cancer. Ann Surg. 2006;243:472-478.

3. Troost EG, Bussink J, Hoffmann AL, Boerman OC, Oyen WJ, Kaanders JH. 18F-FLT PET/CT for early response monitoring and dose escalation in oropharyngeal tumors. $J$ Nucl Med. 2010;51: 866-874.

4. Thorwarth D, Eschmann SM, Holzner F, Paulsen F, Alber M. Combined uptake of [18F]FDG and [18F]FMISO correlates with 
radiation therapy outcome in head-and-neck cancer patients. Radiother Oncol. 2006;80:151-156.

5. Yaromina A, Kroeber T, Meinzer A, et al. Exploratory study of the prognostic value of microenvironmental parameters during fractionated irradiation in human squamous cell carcinoma xenografts. Int $J$ Radiat Oncol Biol Phys. 2011;80:1205-1213.

6. Lambin P, Petit SF, Aerts HJ, et al. The ESTRO Breur Lecture 2009. From population to voxel-based radiotherapy: Exploiting intra-tumour and intra-organ heterogeneity for advanced treatment of non-small cell lung cancer. Radiother Oncol. 2010;96:145-152.

7. Aerts HJ, van Baardwijk AA, Petit SF, et al. Identification of residual metabolic-active areas within individual NSCLC tumours using a pre-radiotherapy (18)fluorodeoxyglucose-PET-CT scan. Radiother Oncol. 2009;91:386-392.

8. Petit SF, Aerts HJWL, van Loon JGM, et al. Metabolic control probability in tumour subvolumes or how to guide tumour dose redistribution in non-small cell lung cancer (NSCLC): An exploratory clinical study. Radiother Oncol. 2009;91:393-398.

9. Aerts HJ, Bussink J, Oyen WJ, et al. Identification of residual metabolic-active areas within NSCLC tumours using a pre-radiotherapy FDG-PET-CT scan: A prospective validation. Lung Cancer. 2012;75:73-76.

10. Aerts HJ, Lambin P, Ruysscher DD. FDG for dose painting: A rational choice. Radiother Oncol. 2010;97:163-164.

11. Bentzen SM. Dose painting and theragnostic imaging: Towards the prescription, planning and delivery of biologically targeted dose distributions in external beam radiation oncology. Cancer Treat Res. 2008;139:41-62.

12. Sovik A, Malinen E, Olsen DR. Strategies for biologic image-guided dose escalation: A review. Int J Radiat Oncol Biol Phys. 2009;73:650-658.

13. Papadopoulos KP, Goel S, Beeram M, et al. A phase 1 open-label, accelerated dose-escalation study of the hypoxia-activated prodrug AQ4N in patients with advanced malignancies. Clin Cancer Res. 2008; 14:7110-7115.

14. Wang JZ, Li XA, Mayr NA. Dose escalation to combat hypoxia in prostate cancer: A radiobiological study on clinical data. Br J Radiol. 2006;79:905-911.

15. De Ruysscher D, Faivre-Finn C, Nestle U, et al. European Organisation for Research and Treatment of Cancer recommendations for planning and delivery of high-dose, high-precision radiotherapy for lung cancer. J Clin Oncol. 2010;28:5301-5310.

16. Thorwarth D, Geets X, Paiusco M. Physical radiotherapy treatment planning based on functional PET/CT data. Radiother Oncol. 2010;96:317-324.

17. Ling CC, Humm J, Larson S, et al. Towards multidimensional radiotherapy (MD-CRT): Biological imaging and biological conformality. Int J Radiat Oncol Biol Phys. 2000;47:551-560.

18. Bentzen SM. Theragnostic imaging for radiation oncology: Dosepainting by numbers. Lancet Oncol. 2005;6:112-117.

19. van Herk M. Errors and margins in radiotherapy. Semin Radiat Oncol. 2004;14:52-64.

20. van Herk M, Remeijer P, Lebesque JV. Inclusion of geometric uncertainties in treatment plan evaluation. Int $J$ Radiat Oncol Biol Phys. 2002;52:1407-1422.

21. van Herk M, Remeijer P, Rasch C, Lebesque JV. The probability of correct target dosage: Dose-population histograms for deriving treatment margins in radiotherapy. Int J Radiat Oncol Biol Phys. 2000;47:1121-1135.

22. McKenzie AL, van Herk M, Mijnheer B. The width of margins in radiotherapy treatment plans. Phys Med Biol. 2000;45: 3331-3342.

23. Stroom JC, de Boer HC, Huizenga H, Visser AG. Inclusion of geometrical uncertainties in radiotherapy treatment planning by means of coverage probability. Int $J$ Radiat Oncol Biol Phys. 1999;43:905-919.
24. Meijer G, Steenhuijsen J, Bal M, De Jaeger K, Schuring D, Theuws J. Dose painting by contours versus dose painting by numbers for stage II/III lung cancer: Practical implications of using a broad or sharp brush. Radiother Oncol. 2011;100:396-401.

25. Baum C, Alber M, Birkner M, Nusslin F. Robust treatment planning for intensity modulated radiotherapy of prostate cancer based on coverage probabilities. Radiother Oncol. 2006;78:27-35.

26. Gordon JJ, Sayah N, Weiss E, Siebers JV. Coverage optimized planning: Probabilistic treatment planning based on dose coverage histogram criteria. Med Phys. 2010;37:550.

27. McShan DL, Kessler ML, Vineberg K, Fraass BA. Inverse plan optimization accounting for random geometric uncertainties with a multiple instance geometry approximation (MIGA). Med Phys. 2006;33:1510-1521

28. Unkelbach J, Oelfke U. Inclusion of organ movements in IMRT treatment planning via inverse planning based on probability distributions. Phys Med Biol. 2004;49:4005-4029.

29. Witte MG, van der Geer J, Schneider C, Lebesque JV, Alber M, van Herk M. IMRT optimization including random and systematic geometric errors based on the expectation of TCP and NTCP. Med Phys. 2007;34:3544

30. Witte M, Shakirin G, Houweling A, Peulen H, van Herk M. Dealing with geometric uncertainties in dose painting by numbers: Introducing the $\Delta \mathrm{VH}$. Radiother Oncol. 2011;100:402-406.

31. Calvo OI, Gutierrez AN, Stathakis S, Esquivel C, Papanikolaou N. On the quantification of the dosimetric accuracy of collapsed cone convolution superposition (CCCS) algorithm for small lung volumes using IMRT. J Appl Clin Med Phys. 2012;13:3751.

32. Siebers JV, Lauterbach M, Keall PJ, Mohan R. Incorporating multi-leaf collimator leaf sequencing into iterative IMRT optimization. Med Phys. 2002;29:952-959.

33. Sonke J-J, Lebesque J, van Herk M. Variability of four-dimensional computed tomography patient models. Int J Radiat Oncol Biol Phys. 2008;70:590-598.

34. van Herk M. Errors and margins in radiotherapy. Semin Radiat Oncol. 2004;14:52-64.

35. Craig T, Battista J, Dyk JV. Limitations of a convolution method for modeling geometric uncertainties in radiation therapy. I. The effect of shift invariance. Med Phys. 2003;30:2001.

36. van Elmpt W, Hamill J, Jones J, De Ruysscher D, Lambin P, Ollers M. Optimal gating compared to 3D and 4D PET reconstruction for characterization of lung tumours. Eur J Nucl Med Mol Imaging. 2011;38:843-855.

37. van Elmpt W, Ollers M, van Herwijnen H, et al. Volume or position changes of primary lung tumor during (chemo-)radiotherapy cannot be used as a surrogate for mediastinal lymph node changes: The case for optimal mediastinal lymph node imaging during radiotherapy. Int J Radiat Oncol Biol Phys. 2011;79:89-95.

38. Rosario T, Ollers MC, Bosmans G, De Ruysscher D, Lambin P, Dekker A. Phased versus midventilation attenuation-corrected respiration-correlated PET for patients with non-small cell lung cancer. J Nucl Med Technol. 2009;37:208-214.

39. Bowen SR, Flynn RT, Bentzen SM, Jeraj R. On the sensitivity of IMRT dose optimization to the mathematical form of a biological imaging-based prescription function. Phys Med Biol. 2009;54:1483-1501.

40. Geets X, Tomsej M, Lee JA, et al. Adaptive biological image-guided IMRT with anatomic and functional imaging in pharyngo-laryngeal tumors: Impact on target volume delineation and dose distribution using helical tomotherapy. Radiother Oncol. 2007;85:105-115, http://dx.doi.org/10.1016/j.radonc.2007.05.010.

41. Duprez F, De Neve W, De Gersem W, Coghe M, Madani I. Adaptive dose painting by numbers for head-and-neck cancer. Int J Radiat Oncol Biol Phys. 2011;80:1045-1055, http://dx.doi.org/10.1016/j.ijrobp.2010.03.028. 